\title{
Control of Hardness Distribution in Friction Stir Welded AA2024-T3 Aluminum Alloy
}

\author{
Saad Ahmed Khodir*, Toshiya Shibayanagi and Masaaki Naka \\ Joining and Welding Research Institute, Osaka University, Ibaraki 567-0047, Japan
}

AA 2024-T3 Aluminum alloy plates of $3 \mathrm{~mm}$ thickness were friction stir butt welded at a constant rotation speed of $1250 \mathrm{~min}^{-1}$ and welding speeds of 50 and $100 \mathrm{~mm} / \mathrm{min}$. Three types of backing materials such as SUS304, pure copper block, and a combination of copper-block with $0.5 \mathrm{~mm}$ SUS304 were used. Controls of temperature history were achieved and their effects on microstructures, hardness distributions, and tensile properties of the joints were investigated. Grain size of the stir zone decreased from $7.4 \mu \mathrm{m}$ in the case of stainless steel to 4.4 and $1.7 \mu \mathrm{m}$ for the cases of a combination backing type and copper-block respectively. As a result of higher heating/or cooling rates, both higher welding speed and copper-block backing material resulted in increased hardness in HAZ and a maximum value was achieved for the combined backing plate at $100 \mathrm{~mm} / \mathrm{min}$ of welding speed. Higher peak temperature was beneficial for higher hardness in stir zone while lower one in HAZ. A maximum tensile strength of the joint was achieved at a welding speed of $100 \mathrm{~mm} / \mathrm{min}$ when the combined backing type was used. The joint efficiency of this case was $93.6 \%$ and this value was the highest among the present joints. [doi:10.2320/matertrans.47.1560]

(Received February 6, 2006; Accepted April 11, 2006; Published June 15, 2006)

Keywords: AA2024-T3, friction stir butt welding, temperature history, grain size, hardness distributions, tensile strength

\section{Introduction}

Friction stir welding (FSW) is a solid state welding process $^{1)}$ and it has been proved to bring about high quality for high strength $\mathrm{Al}$ alloys $(2 \mathrm{xxx}, 7 \mathrm{xxx})$ that are difficult to be welded using conventional fusion welding. ${ }^{2)}$ FSW joint is known to generally possess four zones such as (i) intensively deformed zone called stir zone (SZ), (ii) thermomechanically affected zone (TMAZ), (iii) heat affected zone (HAZ), and (iv) base metal (BM). ${ }^{3}$ )

In general, average grain size decreases with decreasing working temperature and increasing working stain rate. ${ }^{4)}$ Maximum temperature during FSW depends on many factors such as welding speed, rotation speed, vertical pressure, starting temperature of the BM, and active cooling. ${ }^{5)}$ Among these factors welding speed and rotation speed are known to be effective for the maximum temperature, and the temperature increases with decreasing welding speed and increasing rotation speed. Actually many reports succeeded in grain refinement by reducing heat input in relation to these two important welding parameters.

S. Benavides et al. reported that decreasing of the starting temperature of $2024 \mathrm{Al}$ alloy plate from 303 to $240 \mathrm{~K}$ using liquified nitrogen resulted in a significant decrease in the grain size in SZ from 10 to $0.8 \mu \mathrm{m}$. $^{6)}$ This grain refinement was explained as a result of decreasing peak temperature from 603 to $413 \mathrm{~K}$ measured at a distance of $10 \mathrm{~mm}$ away from the welding centerline. Some researchers reported that other age hardening alloys decreased grain size in SZ down to $0.1 \mu \mathrm{m}$ by using a mixture of water, methanol and dry ice for cooling the alloy plate rapidly behind the tool. ${ }^{7)}$ Therefore grain size in SZ can be controlled by controlling temperature during welding.

Precipitates in AA2024-T3 aluminum alloy play dominant roles such as either a hardening agent at small size or a detrimental one to the hardness at large size. Thus dissolution

${ }^{*}$ Ph.D Student, Joining and Welding Research Institute, Osaka University and growth of the precipitate in HAZ would result in a reduction of hardness and consequently lowering the joint efficiency. Dissolution of precipitate also leads to a subsequent recovery of hardness. ${ }^{8)}$ Thus peak temperature, holding time at that temperature, and heating or cooling rates during FWS are the important factors controlling the dissolution and growth behavior of precipitates. Many attempts have been carried out on age hardening aluminum alloys for measuring temperature distribution and its relationship to hardness distribution of FSW joints, while little information about AA2024-T3 aluminum alloy has been reported so far. ${ }^{9,10)}$

Our recent work performed measurements of temperature during FSW and its relation to microstructure and hardness distribution in AA2024-T3 joints. ${ }^{11)}$ It has been pointed out that the over-aging occurred in HAZ at temperature higher than $573 \mathrm{~K}$ and precipitates started to dissolve at around $673 \mathrm{~K}$ and the dissolution was accelerated by increasing temperature. In consequence HAZ lost its hardness and resulted in a reduction of joint efficiency of the joints.

Increasing heating rate reduces the time for precipitates to grow and hence leads to hardening in HAZ. Also increasing cooling rate after peak temperature increases the amount of supersaturated solute that will be available for further precipitation after welding. Therefore decrease of temperature in HAZ below the overaging temperature range or increasing heating or cooling rate through it have become a target to be achieved for the purpose of improving hardness distribution.

The present paper focuses on the control of temperature distribution and thermal history such as heating or cooling rates during FSW as well as their effects on microstructure and hardness distributions of AA2024-T3 aluminum alloy joints. In particular we are have tried to improve the hardness in HAZ by changing temperature history in this zone.

\section{Experimental Procedures}

AA 2024-T3 Aluminum alloy of $3 \mathrm{~mm}$ thick plate was 
Table 1 Chemical composition of AA 2024-T3 base metal.

\begin{tabular}{|c|c|c|c|c|c|c|c|c|c|c|}
\hline Element & $\mathrm{Si}$ & $\mathrm{Fe}$ & $\mathrm{Cu}$ & $\mathrm{Mn}$ & $\mathrm{Mg}$ & $\mathrm{Cr}$ & $\mathrm{Zn}$ & $\mathrm{Ti}$ & $\mathrm{Ti}+\mathrm{Zr}$ & $\mathrm{Al}$ \\
\hline $\begin{array}{l}\text { Nominal } \\
(\text { mass } \%)\end{array}$ & $0.5 \max$ & $0.5 \max$ & $\begin{array}{l}3.8 \min . \\
4.9 \max .\end{array}$ & $\begin{array}{l}0.3 \text { min. } \\
0.9 \max .\end{array}$ & $\begin{array}{l}1.2 \min . \\
1.8 \max .\end{array}$ & $0.1 \max$ & $0.2 \max$ & $0.15 \max$ & $0.2 \max$ & bal. \\
\hline $\begin{array}{c}\text { Actual } \\
(\text { mass } \%)\end{array}$ & 0.06 & 0.08 & 4.1 & 0.50 & 1.4 & 0.01 & 0.04 & 0.02 & 0.02 & bal. \\
\hline
\end{tabular}

Table 2 Mechanical properties of AA 2024-T3 base metal.

\begin{tabular}{lccc}
\hline & $\begin{array}{c}\text { Yield stress } \\
(\mathrm{MPa})\end{array}$ & $\begin{array}{c}\text { Tensile stress } \\
(\mathrm{MPa})\end{array}$ & $\begin{array}{c}\text { Elongation } \\
(\%)\end{array}$ \\
\hline Nominal (min.) & 295 & 440 & 15.0 \\
Actual & 328 & 456 & 20.3 \\
\hline
\end{tabular}
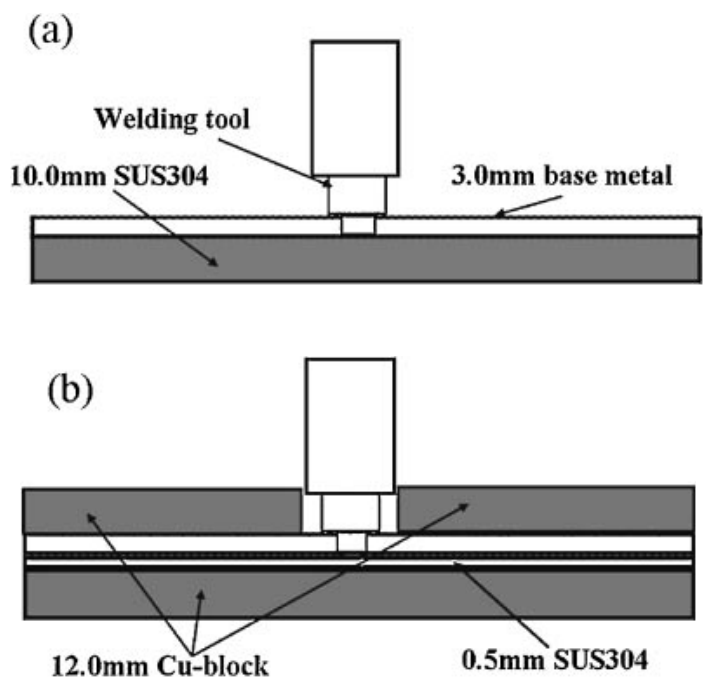

Fig. 1 Schematic of FSW tool with base metal: (a) SUS304 backing, (b) Cu-block backing without or with $0.5 \mathrm{~mm}$ SUS plate.

friction stir butt welded using a tool steel (SKD61) composed of $12 \mathrm{~mm}$ diameter shoulder and $4.0 \mathrm{~mm}$ diameter threaded probe. Tool axis was tilted by 3 degrees with respect to the vertical axis. Rotation speed was kept constant at $1250 \mathrm{~min}^{-1}$ and two welding speeds as 50 and $100 \mathrm{~mm} / \mathrm{min}$ were adopted. The chemical composition and tensile properties of BM are shown in Tables 1 and 2, respectively. As summarized in Table 3, three types of backing materials such as $10 \mathrm{~mm}$ SUS304, $12 \mathrm{~mm}$ pure copper-block, and combina- tion of $0.5 \mathrm{~mm}$ SUS304 plate on $12 \mathrm{~mm}$ copper block were used. As for the second and the third backing types, copper blocks of $12 \mathrm{~mm}$ thick were put on the top surface of the aluminum plates in order to extract more amount of frictional heat during welding.

Figure 1 shows three types of layouts of stainless steel and copper-block as backing materials adopted for the present FSW experiments. Third type adopted a $0.5 \mathrm{~mm}$ SUS304 plate placed between the copper-block and the $2024 \mathrm{Al}$ alloy plate. In this paper, these three backing plates of SUS304, pure copper, and the combination of SUS304 on pure copper block are denoted as backing type 1, type 2, and type 3, respectively.

Temperatures were measured during FSW by utilizing K-type thermocouples of $0.5 \mathrm{~mm}$ diameter at two positions on the bottom surface; welding centerline and at a distance corresponding to a point in HAZ on the advancing side. Thermocouples were set at $1.5 \mathrm{~mm}$ depth from the bottom surface at each measuring position.

Specimens for microstructure observation were machined from the welded plates. The observation was performed on a cross-section in the weld region after mechanical polishing using emery papers (up to grade 1500) followed by polishing performed using $0.3 \mu \mathrm{m}$ alumina contained suspension and colloidal silica suspension. Surface of specimens was etched by Keller's reagent $\left(1 \mathrm{~mL} \mathrm{HF}, 1.5 \mathrm{~mL} \mathrm{HCl}, 2.5 \mathrm{~mL} \mathrm{HNO}_{3}\right.$, and $95 \mathrm{~mL} \mathrm{H}_{2} \mathrm{O}$ ) followed by observation by means of optical microscopy.

Microhardness measurement was carried out after $259.2 \mathrm{ks}$ (three days) from the welding. This time was fixed for all welding conditions and it was quite enough to show the differences in hardness distributions for each conditions. Also the further hardness recovery due to proceeding natural aging especially in HAZ does not have great effect on the comparison of hardness distribution for each case. The measurements were carried out along a mid-thick and at two positions through thickness on the cross section which is transverse to the welding direction with an internal spacing of

Table 3 Welding Conditions.

\begin{tabular}{|c|c|c|c|c|c|}
\hline $\begin{array}{l}\text { Welding } \\
\text { speed } \\
(\mathrm{mm} / \mathrm{min})\end{array}$ & $\begin{array}{l}\text { Rotation speed } \\
\quad\left(\min ^{-1}\right)\end{array}$ & $\begin{array}{c}\text { Type of } \\
\text { backing plate }\end{array}$ & $\begin{array}{l}\text { Thickness of } \\
\text { backing plate } \\
(\mathrm{mm})\end{array}$ & $\begin{array}{c}\text { Type of } \\
\text { covering materials }\end{array}$ & $\begin{array}{c}\text { Thickness of } \\
\text { covering block } \\
(\mathrm{mm})\end{array}$ \\
\hline $\begin{array}{r}50 \\
100\end{array}$ & \multirow{3}{*}{1250} & $\begin{array}{c}\text { Stainless steel } 304 \\
\text { (type 1) }\end{array}$ & 10 & - & - \\
\hline $\begin{array}{r}50 \\
100\end{array}$ & & $\begin{array}{l}\text { Pure Cu-block } \\
\text { (type 2) }\end{array}$ & 12 & Cu-block & 12 \\
\hline $\begin{array}{r}50 \\
100\end{array}$ & & $\begin{array}{c}\text { Combination of Cu-block } \\
\text { with } 0.5 \mathrm{~mm} \text { SUS304 (type } 3 \text { ) }\end{array}$ & 12.5 & Cu-block & 12 \\
\hline
\end{tabular}




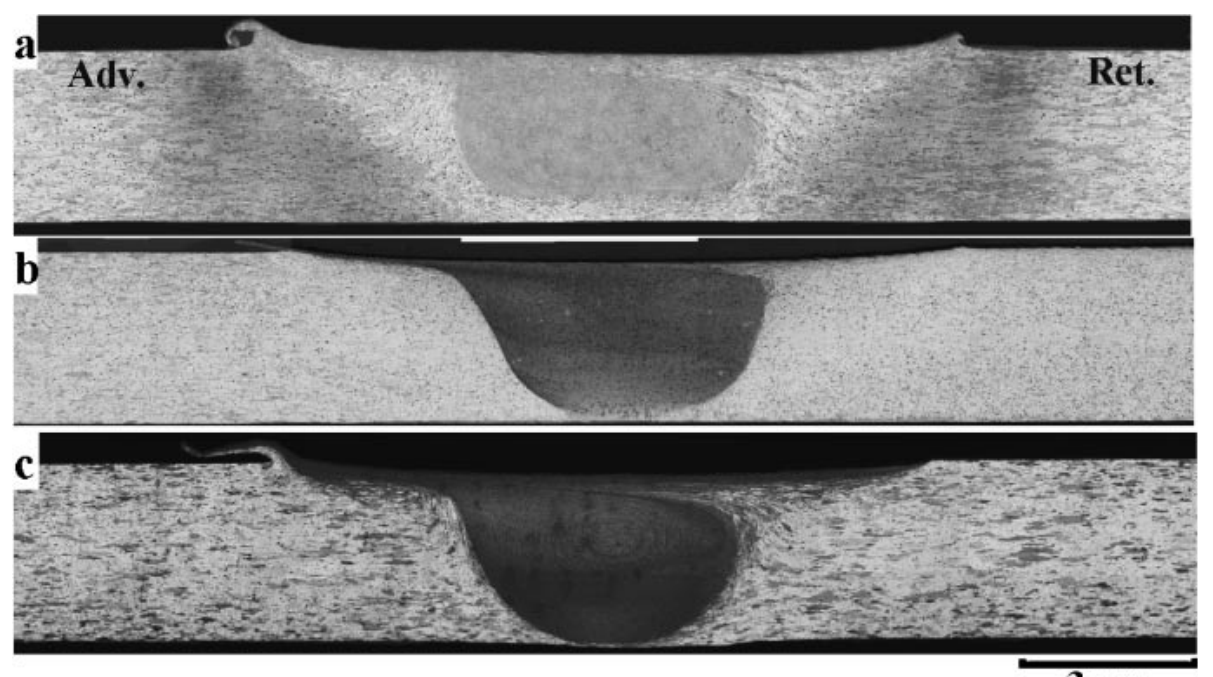

$3 \mathrm{~mm}$

Fig. 2 Macrostructures of the transverse cross section at constant rotation speed $1250 \mathrm{~min}^{-1}$ : (a) type 1 , (b) type 2 , and (c) type 3.
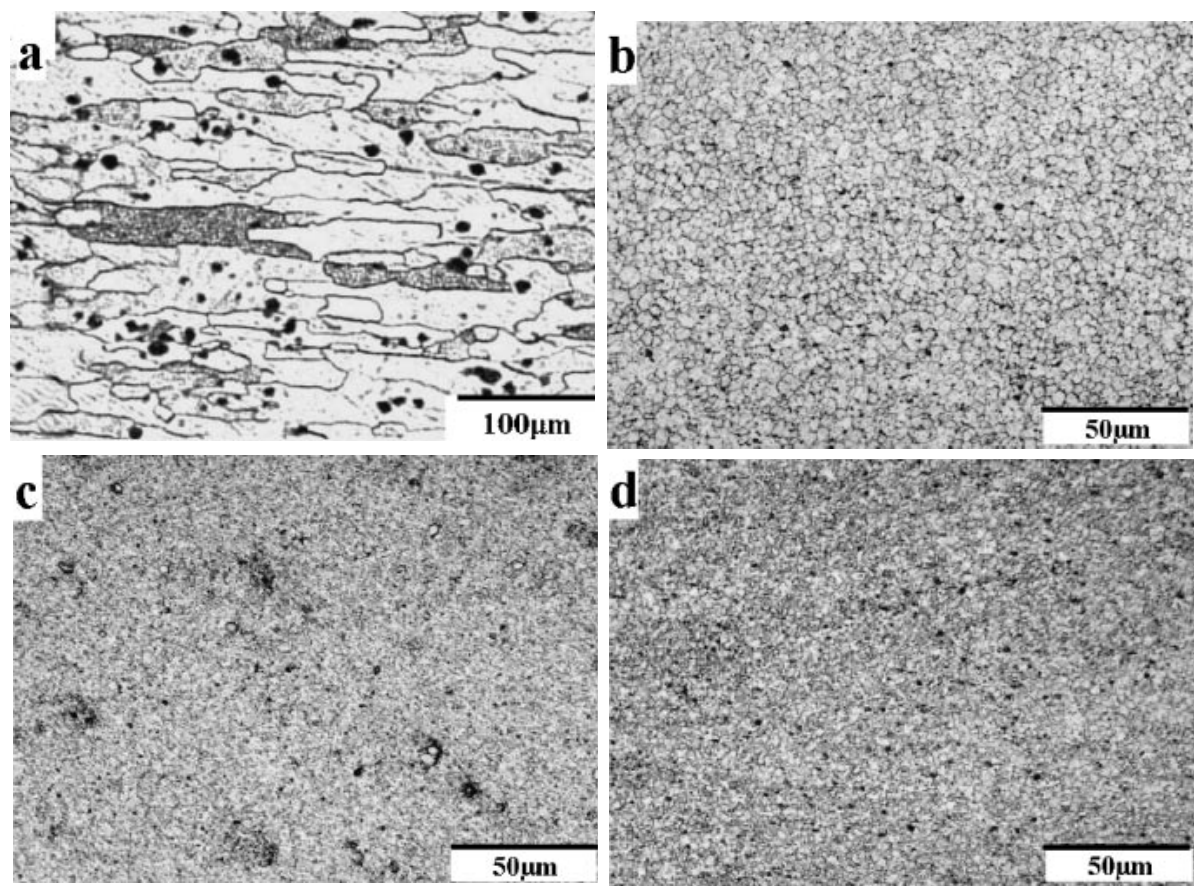

Fig. 3 Optical microstructures of BM and stir zone at the same welding speed of $50 \mathrm{~mm} / \mathrm{min}$ : (a) BM (b) SZ for backing type 1, (c) SZ for type 2 (d) SZ for type 3.

$0.5 \mathrm{~mm}$ under the load of $0.98 \mathrm{~N}$ for $15 \mathrm{~s}$ of loading time. The two positions through thickness are at the welding center-line and along vertical line in HAZ region. The tensile test was carried out at room temperature at a constant crosshead speed of $1 \mathrm{~mm} / \mathrm{min}$. The tensile properties for each rotation speed were evaluated as an average values using three tensile specimens from the same joint for each welding condition.

\section{Results and Discussion}

\subsection{Macrostructure of joints}

Figure 2 shows macroscopic appearances of the crosssection of joints welded at $1250 \mathrm{~min}^{-1}$ utilizing three types of backing materials such as types 1 (a), 2 (b), and 3 (c). All joints are free from neither porosity nor tunnel like defects.
HAZs are recognized as slightly dark areas on both sides of SZ and its contrast becomes less distinctive as the backing material changes from (a) to (c). In addition TMAZ reduces its area and eventually disappears as shown in (b) and (c) for types 2 and 3, respectively.

These macrostructure changes suggest that backing material should be an important factor affecting the evolution process of microstructure during welding. Since copper has much higher thermal conductivity than stainless steel, reduction of the areas of TMAZ and HAZ is explained by an increase in the amount of extraction of frictional heat caused by the welding tool.

\subsection{Microstructure of joints}

Figure 3 shows microstructures of BM and recrystallized 
Table 4 Average grain size in SZ.

\begin{tabular}{cccc}
\hline $\begin{array}{c}\text { Welding speed } \\
(\mathrm{mm} / \mathrm{min})\end{array}$ & $\begin{array}{c}\text { Rotation speed } \\
\left(\mathrm{min}^{-1}\right)\end{array}$ & $\begin{array}{c}\text { Type of } \\
\text { backing plate }\end{array}$ & $\begin{array}{c}\text { Grain size in } \\
\mathrm{SZ}(\mu \mathrm{m})\end{array}$ \\
\hline 50 & & type 1 & 7.1 \\
100 & \multirow{2}{*}{1250} & type 2 & 5.5 \\
\cline { 3 - 4 } 50 & & type 3 & 1.7 \\
100 & & & 1.3 \\
\hline 50 & & & 4.4 \\
100 & & & 3.2 \\
\hline
\end{tabular}

grains in the center region in SZ for joints welded at $50 \mathrm{~mm} /$ min. with three types of backing plates. Microstructure of $\mathrm{BM}$ is shown in Fig. 3(a), representing elongated grains containing randomly distributed second phase particles and inclusions. These grains are several hundred microns long and approximately $70 \mu \mathrm{m}$ wide. On the other hand, SZs of the three joints appear to consist of equiaxed grains with much smaller size compared to the large elongated grains of BM. In addition, the second phase particles were finer and distributed more homogeneously in SZ in the case of type 1 compared with the other two cases of backing materials and BM.

Table 4 represents the average grain size in SZ for the three types of backing materials at welding speeds of 50 and $100 \mathrm{~mm} / \mathrm{min}$. At $50 \mathrm{~mm} / \mathrm{min}$ of welding speed, grain size in SZ decreases from $7.4 \mu \mathrm{m}$ for type 1 to $1.7 \mu \mathrm{m}$ for type 2 while type 3 resulted in the grain size of $4.4 \mu \mathrm{m}$ that is between these two types. At $100 \mathrm{~mm} / \mathrm{min}$, grain size for backing types 1, 2 and 3 decreases from 7.4, 1.7, and 4.4 to $5.5,1.3$, and $3.6 \mu \mathrm{m}$, respectively. Regardless of backing types, grain sizes in SZ of the joints welded at a higher welding speed were lower than those of the joints welded at lower one due to lower heat input associated with less welding speeds.

\subsection{Temperature measurements}

Table 5 summarizes peak temperatures measured at bottom center positions both SZ and at a point in HAZ for three types of backing materials. This table clearly indicates that the joint produced using backing type 2 has the lowest peak temperature of $683 \mathrm{~K}$ in SZ and also the lowest value of $671 \mathrm{~K}$ at a point in $\mathrm{HAZ}$ at $3 \mathrm{~mm}$ from the welding centerline. While backing type 1 brings about the highest temperatures

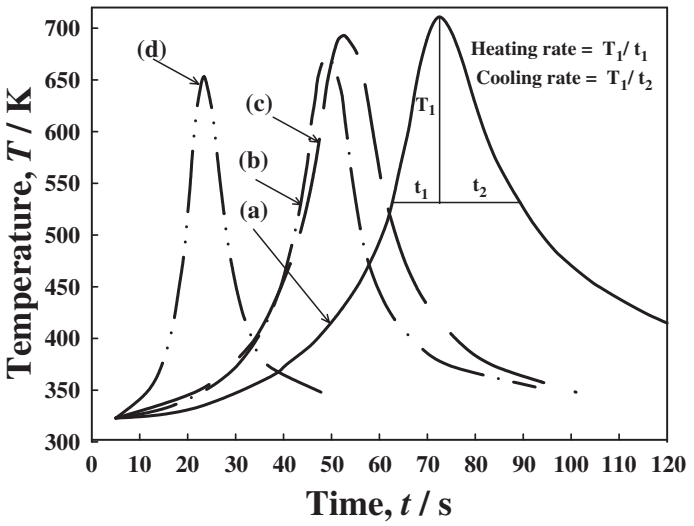

Fig. 4 Temperature change by time at the HAZ during FSW for different backing materials: (a) backing type 1, (b) type 2, (c) type 3 at $50 \mathrm{~mm} / \mathrm{min}$ and (d) type 3 at $100 \mathrm{~mm} / \mathrm{min}$ welding speed.

in both zones; $786 \mathrm{~K}$ in $\mathrm{SZ}$ and $711 \mathrm{~K}$ at a point in HAZ at $6 \mathrm{~mm}$ from the weld centerline. For the case of backing type 3 the temperatures were between these two cases. At $100 \mathrm{~mm} /$ min of welding speed the temperatures in two zones decreased for every backing type. A large incremental of temperature as $103 \mathrm{~K}$ is observed in SZ by changing backing type from 1 to 2 . This could be attributed to a considerable amount of heat extraction through the copper block used in type 2 .

Figure 4 shows temperature histories at a point in HAZ during FSW for the backing type 1 (a), type 2 (b), type 3 at a welding speed of $50 \mathrm{~mm} / \mathrm{min}$ (c), and type 3 (d) at a welding speed of $100 \mathrm{~mm} / \mathrm{min}$. In the present study "the welding time" is defined as the entire time starting from $535 \mathrm{~K}$ to the peak temperature followed by cooling down to this temperature. This temperature range was selected because longer time at that temperature range increases the rate of precipitation during over-aging rather than dissolution rate. ${ }^{8)}$ Peak temperatures are in the order of backing type 1, type 3 , type 2 at $50 \mathrm{~mm} / \mathrm{min}$ and type 3 at $100 \mathrm{~mm} / \mathrm{min}$ of welding speed indicating the reduction of welding time. The combined effect of $\mathrm{Cu}$-block and higher welding speed results in fastest welding time as shown in (d). The calculated welding times from this figure were $26,10,18$, and 6 seconds for the backing type 1 , type 2 , type 3 at $50 \mathrm{~mm} / \mathrm{min}$ and type 3 , at $100 \mathrm{~mm} / \mathrm{min}$, respectively.

Table 5 Temperature measured in SZ and HAZ.

\begin{tabular}{|c|c|c|c|c|c|}
\hline $\begin{array}{l}\text { Welding } \\
\text { speed } \\
(\mathrm{mm} / \mathrm{min})\end{array}$ & $\begin{array}{l}\text { Rotation speed } \\
\qquad\left(\min ^{-1}\right)\end{array}$ & $\begin{array}{c}\text { Type of } \\
\text { backing plate }\end{array}$ & $\begin{array}{c}\text { Thickness of } \\
\text { backing plate } \\
(\mathrm{mm})\end{array}$ & $\begin{array}{c}\mathrm{SZ} \\
\text { Temperature } / \mathrm{K}\end{array}$ & $\begin{array}{c}\text { HAZ } \\
\text { Temperature } / \mathrm{K}\end{array}$ \\
\hline 50 & \multirow{3}{*}{1250} & $\begin{array}{c}\text { Stainless steel } 304 \\
\text { (type 1) }\end{array}$ & 10 & 768 & $\begin{array}{c}711 \\
\text { (at } 6 \mathrm{~mm} \text { from WCL) }\end{array}$ \\
\hline 50 & & $\begin{array}{l}\text { Pure Cu-block } \\
\quad \text { (type 2) }\end{array}$ & 12 & 683 & $\begin{array}{c}671,535 \\
\text { (at } 3,6 \mathrm{~mm} \text { from WCL) }\end{array}$ \\
\hline 100 & & $\begin{array}{c}\text { Combination of Cu-block } \\
\text { with } 0.5 \mathrm{~mm} \mathrm{SUS304} \text { (type } 3 \text { ) }\end{array}$ & 12.5 & 708 & $\begin{array}{c}648 \\
\text { (at } 3 \mathrm{~mm} \text { from WCL) }\end{array}$ \\
\hline
\end{tabular}

WCL: weld center-line 


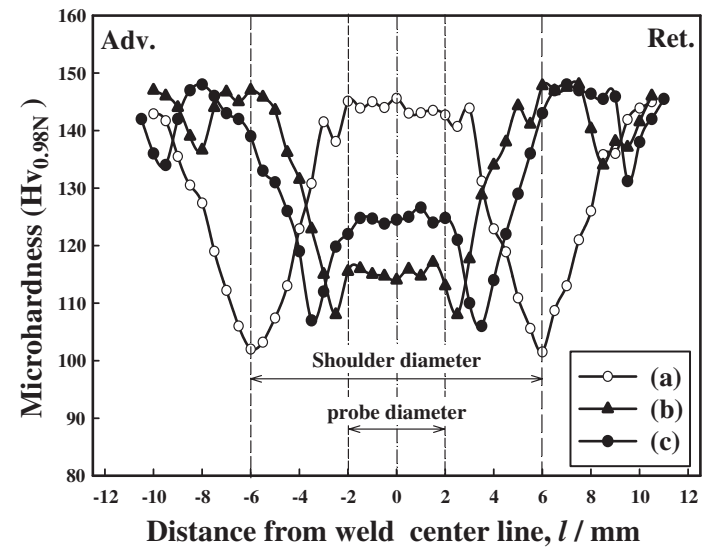

Fig. 5 Hardness profiles at mid thickness transverse to welding directions of the weld joint for (a) backing type 1, (b) type 2, and (c) type 3.

Heating and cooling rates are defined as $T_{1} / t_{1}$ and $T_{1} / t_{2}$ in Fig. 4, respectively in the present study. $T_{1}$ is increment of temperature from $535 \mathrm{~K}$ to peak value. $t_{1}$ and $t_{2}$ are time required for reaching peak temperature and time for reaching $535 \mathrm{~K}$ from peak temperature, respectively. For backing types 1 and 2, heating rates are 17.25 and $25.0 \mathrm{~K} / \mathrm{s}$, respectively. Cooling rates for backing types of 1 and 2 were 11.5 and $22.2 \mathrm{~K} / \mathrm{s}$, respectively. For backing type 3, heating rates were 20.8 , and $32.6 \mathrm{~K} / \mathrm{s}$ for welding speeds of 50 and $100 \mathrm{~mm} / \mathrm{min}$., respectively. Cooling rates for welding speeds of 50 and $100 \mathrm{~mm} / \mathrm{min}$. are 17.0 , and $28.12 \mathrm{~K} / \mathrm{s}$, respectively. Baking type 3 at a welding speed of $100 \mathrm{~mm} / \mathrm{min}$ has the highest cooling or heating rates while backing type 1 at $50 \mathrm{~mm} / \mathrm{min}$ has the lowest ones.

Average grain size in SZ depends mainly on the peak temperature and strain rate. ${ }^{10-13)}$ The grain size in SZ increases with increasing peak temperature and decreasing strain rate. Since all the welds were fabricated at constant rotation speed in the present study, strain rate is constant and therefore, grain size in SZ depends only on the peak temperature. For example, in case of backing type 1 the largest grain size is obtained because of the highest peak temperature as shown in Table 5. Thus lower grain size in SZ was brought about by decreasing peak temperature due to higher thermal conductivity of pure copper than that of stainless steel. For the backing type 3, the $0.5 \mathrm{~mm}$-thick SUS304 plate added onto the pure copper bock slightly decreases the amount of heat extraction through the copper block which in turn increases the peak temperature resulting in larger grain size. Therefore, grain size in SZ is expected to be controlled easily by utilizing suitable backing materials.

\subsection{Hardness of joints}

Figure 5 shows profiles of microhardness along a line at mid-thick position on transverse cross-section of joints welded at a welding speed of $50 \mathrm{~mm} / \mathrm{min}$ using backing plates of type 1 (a), type 2 (b) and type 3 (c). In case of type 1 as shown in (a), hardness beyond $10 \mathrm{~mm}$ from the weld center is $146 \mathrm{Hv}$ that is almost the same as that of BM. At about $10 \mathrm{~mm}$ from the weld center line, hardness starts to decrease and reaches a minimum value of about $102 \mathrm{Hv}$ at $6 \mathrm{~mm}$ from the weld center line. The minimum points are located on both

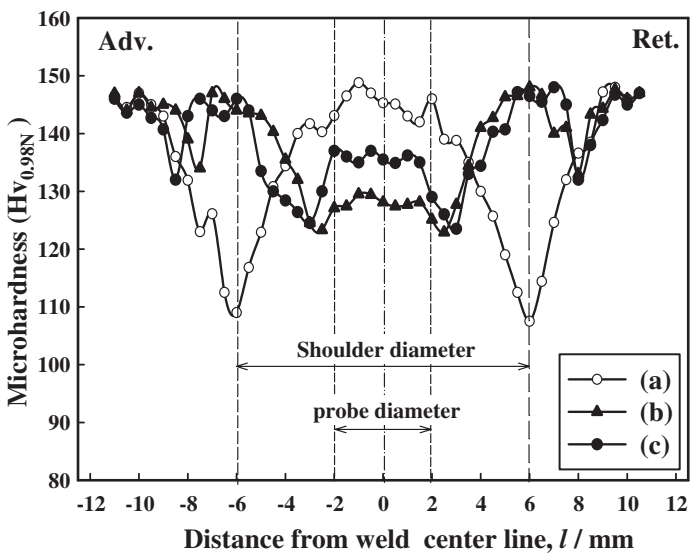

Fig. 6 Hardness profiles at $100 \mathrm{~mm} / \mathrm{min}$ welding speed: (a) for backing type 1 (b) type 2 , and (c) type 3 .

sides of HAZ. As coming to the weld center line through SZ beyond that minimum point, hardness turns to increase and reaches again equal value to that of BM.

In 2024-T3 base metal, the initial hardening precipitates is Guinier Preston Bagarystskii (GPB) zones. ${ }^{14)}$ These zones dissolve during heating resulting in very fine $\mathrm{S}^{\prime}$ or $\mathrm{S}$ precipitates $\left(\mathrm{Al}_{2} \mathrm{CuMg}\right)$ without or slightly changes in hardness. Upon continuous heating to higher temperature $\mathrm{S}^{\prime}$ or $\mathrm{S}$ precipitates coarse and lost their coherency. ${ }^{14,15)}$ Softening behavior observed in HAZ could be caused by a coarsening and/or a dissolution of $\mathrm{S}^{\prime}$ or $\mathrm{S}$ precipitates during welding. Hardening in SZ could be attributed to the formation of new GPB zones at room temperature after welding. ${ }^{14)}$ Most of precipitates dissolved both in TMAZ and SZ during welding where peak temperature in SZ is $786 \mathrm{~K}$ that is higher than the solution treatment temperature of this alloy. Therefore the increase of temperature is sufficient for precipitates to be dissolved during welding and in consequence precipitation occurs again in the weld during the natural aging for three days after welding.

In case of backing type 2 as shown in (b), a hardness minimum of $108 \mathrm{Hv}$ appears in HAZ that is located at about $2.5 \mathrm{~mm}$ from the welding center-line. This minimum value is larger than that obtained for the case of type 1 . At $6 \mathrm{~mm}$ from the welding center-line, hardness is almost equal to that of $\mathrm{BM}$, while SZ show less value in turn. Increase of hardness observed in HAZ at about $6 \mathrm{~mm}$ from the welding center-line could be expected to the presence of very fine $S^{\prime}$ or $S$ phase precipitates $^{14)}$ since peak temperature measured at this position is $533 \mathrm{~K}$ where it is lower than the coarsening and/or dissolution temperature range as seen in Fig. 4. Therefore only artificial aging occurred in this region. The temperatures measured in SZ and HAZ at about $3 \mathrm{~mm}$ from weld center line are 683 and $671 \mathrm{~K}$ respectively. These temperatures are within coarsening and/or dissolution temperature ranges. So the coarsening of precipitates results in the reduction of hardness in these two regions. This change of hardness distribution clearly suggests that selection of backing plate is quite important for controlling mechanical properties of FSW joints as well as microstructure.

In case of backing type 3 as shown in (c), hardness distribution slightly changes from the case of backing type 2 . 


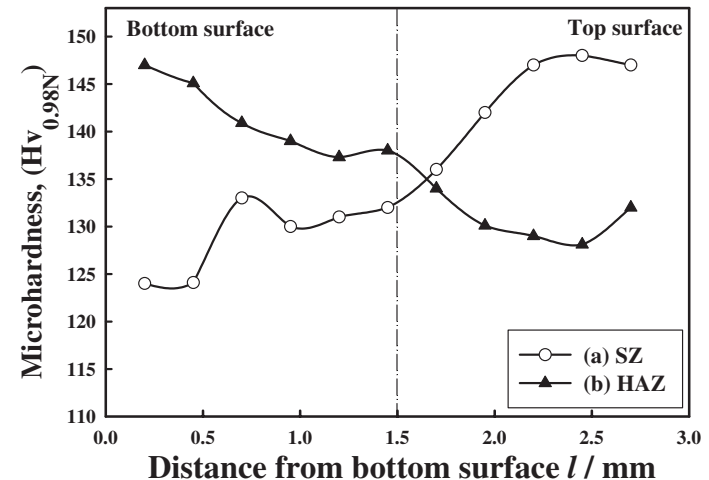

Fig. 7 Hardness distribution from top to bottom surface in backing type 3 at $100 \mathrm{~mm} / \mathrm{min}$ of welding speed: (a) SZ, (b) HAZ at $4 \mathrm{~mm}$ from welding center line.

SZ becomes harder due to higher peak temperature of $744 \mathrm{~K}$ which was sufficient for enhancing dissolution rather than coarsening of precipitations. The softened zones observed in HAZ shifted about $0.5 \mathrm{~mm}$ out of the SZ compared with the case of backing type 2). For types 2 and 3, at about 7-8 mm from the weld center-line, hardness slightly decreases. The hardness minimum located in that area could be expected to the dissolution of some fine $S^{\prime}$ or $S$ precipitates ${ }^{15)}$ as a result of lower cooling rate at that area due to a gap between the welding tool and the covering copper block that are schematically shown in Fig. 1(b).

Figure 6 shows three hardness profiles at higher welding speed of $100 \mathrm{~mm} / \mathrm{min}$ measured along the mid-thick line (a) for backing type 1, (b) type 2 and (c) for backing type 3 . In case of backing type 1 as shown in (a) comparing with Fig. 5(a), no significant hardness change appears in SZ both at lower and higher welding speeds. On the other hand, HAZ becomes harder and especially higher welding speed brings about further hardening of HAZ and a maximum value of about $110 \mathrm{Hv}$ at $6.0 \mathrm{~mm}$ from the weld center line is achieved while the value is still much lower than that of BM.

For backing types 2 and 3, as shown in (b) and (c), respectively, HAZ shows further increase of hardness and the maximum value increases by $14-16 \mathrm{Hv}$ than that welded at lower welding speed when compared with Figs. 5(b) and (c). The difference of hardness values in HAZ between types 2 and 3 is about $1-2 \mathrm{Hv}$ while larger difference of about 14 $16 \mathrm{Hv}$ is obtained between backing type 1 and types 2 or 3 . On the contrary, SZ for backing type 3 becomes harder than type 2 . In general higher welding speed results in higher hardness since less frictional heat is introduced into materials and the present data is well consistent with this general rule. The results shown in Figs. 5 and 6 suggest that improvement of hardness distribution should be realized not only by higher welding speed but also by selecting type of backing materials.

Figure 7 shows two hardness distributions obtained for backing type 3 at $100 \mathrm{~mm} / \mathrm{min}$ of welding speed; (a) along the vertical direction from the top surface through bottom surface in SZ at the weld center-line and (b) along vertical line in HAZ at about $4 \mathrm{~mm}$ from the weld center line. Hardness near the top surface in SZ is higher than that near the bottom surface as shown in (a) and vice versa in HAZ as shown in (b). Since the tool shoulder dominates heat generation during FSW, ${ }^{16}$ ) temperature should decrease toward the bottom surface. Higher temperature is beneficial for SZ to increase its hardness during the natural aging (new formation of GPB zones), while HAZ should experience temperature as lower as possible during welding. Additionally extraction of heat by copper block brings about steeper temperature gradient in the joint.

In the present experiment, temperature during FSW is sufficiently high and the duration at the temperature is sufficiently long to make a dominant influence on precipitation process of this alloy. There is a possibility of aging process during welding both in SZ and HAZ where the initial precipitates evolve likewise dissolution, over aging and artificial aging that are functions of temperature and holding time. Therefore, increase of the heating or cooling rates especially during the coarsening temperature range would improve hardness distributions in HAZ since increasing heating rate reduces the time for the growth of precipitates and hence leads to the increase of hardness. Also raising of cooling rate after peak temperature increases the amount of supersaturated solute that will be available for further precipitation at room temperature after welding.

Since SZ is considered to have experienced higher temperature than the coarsening temperature range (573$673 \mathrm{~K}$ ), dissolution and overaging behaviors proceed simultaneously. Increasing temperature higher than $673 \mathrm{~K}$ or increasing heating and cooling rates should increase the rate of dissolution rather than the overaging rate. Increasing dissolution rate results in higher hardness due to precipitation of new GPB zones at room temperature and its volume fraction increases with increasing temperature. Therefore, increasing temperature from the bottom toward the top surface results in hardening of SZ along this direction as shown in Fig. 7(a). Also, the higher hardness in SZ of the joints fabricated using backing types 1 and 3 compared with type 2 is related to higher temperature during the entire process of welding.

On the other hand, HAZ experienced lower temperature than SZ during welding. It undergoes maximum temperature slightly higher than the coarsening temperature range. In that temperature range the coarsening rate increases rather than the dissolution rate, thus decreasing peak temperature and increasing heating or cooling rates should decrease the coarsening rate. Therefore, the temperature gradient decreasing from the top surface toward the bottom one should change the hardness distribution from the top to the bottom as shown in Fig. 7(b). Comparing the hardness values at $6 \mathrm{~mm}$ from the weld center for different backing plates shown in Figs. 5(a) and (b), it is obvious that using of copper block resulted in higher value of hardness due to lower peak temperature and higher heating/cooling rates as indicated in Fig. 4.

At higher welding speed of $100 \mathrm{~mm} / \mathrm{min}$., hardness increased in SZ and especially in HAZ for the backing types 2 and 3 . This was also due to higher heating and cooling rates associated with the increased welding speed although the peak temperatures decreased in SZ for each backing type. Therefore in order to obtain higher hardness in SZ, the peak temperature should be higher than the solid solution temper- 
Table 6 Mechanical properties of welded joints.

\begin{tabular}{|c|c|c|c|c|c|c|}
\hline $\begin{array}{c}\text { Type of } \\
\text { backing plate }\end{array}$ & $\begin{array}{c}\text { Welding } \\
\text { speed } \\
(\mathrm{mm} / \mathrm{min})\end{array}$ & $\begin{array}{l}\text { Rotation speed } \\
\qquad\left(\min ^{-1}\right)\end{array}$ & $\begin{array}{l}\text { Yield strength } \\
\quad(\mathrm{MPa})\end{array}$ & $\begin{array}{l}\text { Tensile strength } \\
\qquad(\mathrm{MPa})\end{array}$ & $\begin{array}{c}\text { Elongation } \\
(\%)\end{array}$ & $\begin{array}{c}\text { Joint } \\
\text { efficiency } \\
\%\end{array}$ \\
\hline \multirow{2}{*}{1} & 50 & \multirow{6}{*}{1250} & 286 & 382 & 9.6 & 83.8 \\
\hline & 100 & & 247 & 335 & 5.6 & 73.4 \\
\hline \multirow{2}{*}{2} & 50 & & 272 & 340 & 8.0 & 74.6 \\
\hline & 100 & & 276 & 374 & 6.0 & 82.1 \\
\hline \multirow{2}{*}{3} & 50 & & 275 & 385 & 11.0 & 84.4 \\
\hline & 100 & & 284 & 427 & 14.3 & 93.6 \\
\hline
\end{tabular}

ature and/or heating and cooling rates should be increased with keeping temperature higher than the temperature range where the coarsening of precipitates takes place.

The present work aims to obtain hardness distribution as flat as possible throughout the welded joints by selecting backing materials that can control temperature distribution in terms of thermal history during FSW. The best condition realizing hardness distribution close to the ideal state in the present work is obtained by utilizing the backing plate of type 3 together with at welding speed of $100 \mathrm{~mm} / \mathrm{min}$., although the distribution still showed hardness drops in SZ. Hardness distributions were measured after $259.2 \mathrm{ks}$ from welding and so the precipitation seems to have been proceeding. Thus additional natural aging or artificial aging treatments are expected to be effective for reducing the fluctuation of hardness. Also, designing backing materials composed of suitable materials having appropriate thermal conductivity and heat capacity would be promising for obtaining little fluctuation of hardness throughout the joints friction stir welded.

\subsection{Tensile properties of joints}

Table 6 shows the tensile properties of joints welded at welding speeds of 50 and $100 \mathrm{~mm} / \mathrm{min}$ for three different types of backing plates. All tensile properties of the joints are lower than those of BM, and especially the elongations are much lower. The maximum value of elongation to fracture is $14.3 \%$ in case of the backing type 3 at a welding speed of $100 \mathrm{~mm} / \mathrm{min}$. At $50 \mathrm{~mm} / \mathrm{min}$ of welding speed, tensile strength, yield strength, and elongation of backing type 2 are lower than those of backing type 1 although larger minimum values of hardness are obtained in case of backing type 2 . This could be attributed to a kissing bond at the welding root of the joint. The maximum tensile strength of the joints is $427 \mathrm{MPa}$ which is achieved at $100 \mathrm{~mm} / \mathrm{min}$ of welding speed and using backing type 3, where higher hardness is obtained. The joint efficiency is $93.6 \%$ for this condition.

Tensile properties of FSW joints mainly depend on the welding defects and hardness distributions of joints, of which are functions of the welding parameters. When joints are free from these defects, their tensile properties are affected dominantly by hardness distributions. ${ }^{17)}$ As seen in Fig. 6, higher hardness in HAZ could have resulted in strengthening of joints welded using backing type 3 at higher welding speed.

Although the hardness distributions with higher value is realized in cases of backing types 2 and 3, the tensile properties of joints in the case of backing type 2 is much lower than that of backing type 3 . The lower tensile properties of joints using backing type 2 could be attributed to the lower temperature on the bottom surface of butt welded plate which should have affected the metal flow in this area especially at higher welding speed, where kissing bond appeared. The addition of a $0.5 \mathrm{~mm}$ SUS304 plate to the $\mathrm{Cu}-$ block keeps temperature high at the bottom surface which made joints free from kissing bond.

When a tensile load is applied to the joint, the stress and strain concentration takes place in the lowest-strength part or region in the joint, and consequently the joint is fractured in this region. Thus the improvement of hardness distributions resulted in the increase of joint strength and joint efficiency as well.

\section{Conclusions}

Three types of backing materials were utilized to find out a way to control microstructure and mechanical properties such as hardness distribution and tensile properties of the joints of AA 2024-T3 aluminum alloy. The following results were obtained.

(1) Reduction of grain size in SZ was significantly realized when using type 2 of backing material at the same welding conditions. Larger grain size in SZ was obtained using backing type 1 .

(2) Hardness changed greatly in SZ and HAZ depending on backing materials. The position of hardness minimum shifted from 6 to $3 \mathrm{~mm}$ from the weld center and the value increased and reached the maximum among the present joints in case of the backing type 3 and at a welding speed of $100 \mathrm{~mm} / \mathrm{min}$.

(3) Higher peak temperature or higher heating and cooling rates with keeping temperature higher than the coarsening temperature range of precipitates were effective for realizing higher hardness in SZ while lower temperature and higher heating or cooling rate are required for HAZ.

(4) Backing plate of type 3 brought about the best tensile properties and the joint efficiency was $93.6 \%$.

\section{Acknowledgements}

This work was supported by a grant-in-aid for scientific research B (project No. 17360353) and a grant-in-aid for 
cooperative research project of nationwide joint-use Research Institutes on Development Base of Joining Technology for new Metallic Glasses and Inorganic Materials from the Ministry of Education, Culture, Sports, Science and Technology, Japan.

\section{REFERENCES}

1) C. J. Dawes and W. M. Thomas: Weld. J. 75 (1996) 41-45.

2) C. G. Rhodes, M. W. Mahoney, W. H. Bingel, R. A. Spurling and C. C. Bampton: Scripta Mater. 36 (1997) 69-75.

3) O. V. Flores, C. Kennedy, L. E. Murr, D. Brown, S. Pappu, M. N. Brook and J. C. McClure: Scripta Mater. 38 (1998) 703-708.

4) C. I. Chang, C. J. Lee and J. C. Huang: Scripta Mater. 51 (2004) 509514.

5) R. S. Mishra and Z. Y. Ma: Mater. Sci. Eng. R 50 (2005) 1-78.

6) S. Benavides, Y. Li, L. E. Murr, D. Brown and J. C. McClure: Scripta Mater. 41 (1999) 809-815.

7) J.-Q. Su, T. W. Nelson and C. J. Sterling: J. Mater. Res. 18 (2003)
$1757-1760$.

8) H. R. Shercliff, J. R. Michael, A. Taylor and T. L. Dickerson: Mecanique \& Industries 6 (2005) 25-35.

9) L. E. Murr, G. Liu and J. C. Mcclure: J. Mater. Sci. 33 (1998) $1243-$ 1251.

10) Y. S. Sato, M. Urata and H. Kokawa: Metall. Mater. Trans A 33 (2002) 625-632.

11) S. A. Khodir, T. Shibayanagi and M. Naka: Mater. Trans. 47 (2006) 185-193.

12) Y. Li, L. E. Murr and J. C. McClure: Mater. Sci. Eng. A 271 (1999) 213-223.

13) M. W. Mohoney, C. G. Rhodes, J. G. Flintoff, R. A. Spurling and W. H. Bingel: Metall. Mater. Trans A 29 (1998) 1955-1964.

14) C. Genevois, A. Deschamps, A. Denquin and B. Doisneau-cottignies: Acta Mater. 53 (2005) 2447-2458.

15) M. J. Jones, P. Heurtier, C. Desrayaud, F. Montheillet, D. Allehaux and J. H. Driver: Scripta Mater. 52 (2005) 693-697.

16) W. Tang, X. Guo, J. C. McClure and L. E. Murr: Mater. Process. Manufact. Sci. 7 (1998) 163-172.

17) H. J. Liu, H. Fujii, M. Maeda and K. Nogi: J. Mater. Process. Tech. (2003) 692-696. 